\section{Tyrosine kinase inhibitors for diabetes}

\section{By Brian Moy, Staff Writer}

Since the kinase inhibitors Gleevec imatinib from Novartis AG and Sutent sunitinib from Pfizer Inc. were approved to treat various cancer indications, academics have been looking to take advantage of the offtarget promiscuity of these drugs by aiming them at diseases outside of oncology, including rheumatoid arthritis, psoriasis and Crohn's disease. Indeed, studies have already shown that patients with chronic myeloid leukemia and type 2 diabetes experienced improvements in the latter condition when treated with Gleevec. ${ }^{1}$

Now, researchers at the University of California, San Francisco report that tyrosine kinase inhibitors also could have utility in type 1 diabetes. The team, led by Jeffrey Bluestone, director of the UCSF Diabetes Center, found that Gleevec decreased insulitis and full-blown diabetes in both prediabetic and new-onset diabetic mice compared with what was seen in mice that received oil control solution. ${ }^{2}$

As reported in the Proceedings of the National Academy of Sciences, no mice given the Bcr-Abl tyrosine kinase inhibitor developed diabetes during seven weeks of treatment, whereas about $40 \%$ of control mice developed disease. Upon termination of treatment, $20 \%$ of the treated mice became progressively diabetic by 30 weeks of age compared with $71 \%$ of control mice.

An unexpected finding, according to the researchers, was that "limiting treatment to 8-10 weeks after disease onset was sufficient to reverse diabetes and induce long-term remission," and the immune cells that had been attacking the islets before treatment were no longer doing so. The results raise the possibility that short-term treatment could have long-lasting effects.

Sutent, a small molecule inhibitor of multiple receptor tyrosine kinases including c-Kit (CD117), platelet-derived growth factor receptor (PDGFR) and the macrophage colony-stimulating factor receptor (C-FMS; CSF1R), produced similar results as Gleevec.

As a result, the UCSF researchers concluded that Bcr-Abl, Gleevec's primary target, was probably not the key to blocking diabetes.

To find out which target was responsible for the efficacy in type 1 diabetes, the researchers treated mice with a tyrosine kinase inhibitor targeting c-Kit and C-FMS and showed that the molecule was not sufficient to block disease progression. In contrast, neutralization of PDGFR rapidly reversed diabetes in 5 of 6 mice treated for 10 days compared with only 1 of 6 mice treated with control Ig. According to the authors, this suggests that "inhibition of PDGFR is critical to reverse diabetes."

Gleevec has also been shown to block other tyrosine kinases, including PDGFR. ${ }^{3}$

"Since there are very few drugs available to treat type 1 diabetes, our findings are significant because we show that a drug already proven to be effective to treat cancer can potentially be used to prevent and even reverse type 1 diabetes in recently diagnosed patients," said Bluestone.

"We are certainly optimistic about the role of tyrosine kinase inhibitors in autoimmune disease, including type 1 diabetes, and this paper is a good step in that direction," Gideon Bollag, SVP of research at Plexxikon Inc., told SciBX.

Bollag was an author on the PNAS article, and Plexxikon provided reagents for the study. The company's PLX3397, a tyrosine kinase inhibitor specifically targeting c-Kit and C-FMS, is in late preclinical development for rheumatoid arthritis (RA) and other autoimmune diseases, including type 1 diabetes, lupus and multiple sclerosis (MS).

Sutent is approved to treat gastrointestinal stromal tumors (GIST) and renal cell carcinoma (RCC), whereas Gleevec is approved for GIST and chronic myeloid leukemia (CML).

For the first nine months of 2008, Gleevec posted sales of $\$ 2.8$ billion, whereas Sutent sales were $\$ 627$ million.

\section{Kinase hurdles}

Denise Faustman, director of the immunobiology laboratory at Massachusetts General Hospital and an associate professor of medicine at Harvard Medical School, told SciBX she wanted to see more animal data, including long-term follow-up studies that use tyrosine kinase inhibitors in a diabetes model that more closely resembles human disease.

Faustman added it would be interesting to study the inhibitors in mice with full-blown type 1 disease.

"While it is great that they cured not yet diabetic mice and very newly onset diabetic mice, it will be important to advance the study into the appropriate framework by treating long-term diabetic mice," she said. "These studies will help us understand the potential applicability to humans with the disease."

Faustman said that the effects of Gleevec and Sutent might be muted in animals with more advanced disease because the drugs in the PNAS study didn't modify leukocyte accumulation within the pancreas, a hallmark of type 1 diabetes. "Although treatment with imatinib prevented clinical disease onset, it did not reduce leukocyte infiltrates on top of the pancreatic islets," she noted. "It would be important to see data with long-term follow-up of the animals beyond three weeks 


\section{TARGETS \& MECHANISMS}

to further investigate drug efficacy."

Bluestone acknowledged that the use of tyrosine kinase inhibitors to treat mice-or humans-with full-blown type 1 diabetes is unlikely to work. Tyrosine kinase inhibitors "can only be used in mice that have residual insulin-producing islet cells to protect. Once the mice are diabetic for a period of time, all of their islets are gone and it is too late to treat them unless an islet transplantation is performed," he told SciBX.

\section{Kinase safety}

In addition to efficacy in patients with advanced disease, the safety of tyrosine kinase inhibitors is likely to be a key issue, as the risk vs. benefit equation is much different in cancer compared with a chronic condition like diabetes.

Side effects of Gleevec include severe fluid retention, heart failure, liver problems, abnormal bleeding and skin blistering, whereas Sutent has been reported to increase blood pressure and cause heart problems.

Indeed, the labels suggest the drugs could elicit "significant side effects when deployed to a larger population, including those at risk for developing diabetes, among them children," said Matthias von Herrath, director of the Diabetes Center at La Jolla Institute for Allergy \& Immunology. "Prolonged application of such inhibitors is not really easily possible."

Thus, said Bluestone, it will be important to investigate if tyrosine kinase inhibitors can be used in the short term and still elicit a long- term effect in preventing and/or reversing disease. "We don't want children with type 1 diabetes to be taking immunosuppressive drugs for their entire lives rather than taking insulin," he said.

Ongoing studies by Bluestone and colleagues are attempting to further investigate the mechanism of action behind tyrosine kinase inhibitors and their ability to reverse type 1 diabetes. The researchers are also seeking to identify more specific tyrosine kinase inhibitors, such as a PDGFR-specific inhibitor, to achieve a more targeted effect.

A patent application has been filed by the UCSF researchers for the use of tyrosine kinase inhibitors to treat diabetes and is available for licensing in the U.S.

Moy, B. SciBX 1(45); doi:10.1038/scibx.2008.1094

Published online Dec. 18, 2008

\section{REFERENCES}

1. Flanagan, M. BioCentury 13(31), A12-A13; July 11, 2005

2. Louvet, C. et al. Proc. Natl. Acad. Sci. USA; published online Nov. 17, 2008; doi:10.1073/pnas.0810246105

Contact: Jeffery Bluestone, University of California, San Francisco, Calif. e-mail: jbluest@diabetes.ucsf.edu

3. Buchdunger, E. et al. J. Pharmacol. Exp. Ther. 295, 139-145 (2000)

\section{COMPANIES AND INSTITUTIONS MENTIONED}

Harvard Medical School, Boston, Mass.

La Jolla Institute for Allergy \& Immunology, La Jolla, Calif. Massachusetts General Hospital, Boston, Mass.

Novartis AG (NYSE:NVS; SWX:NOVN), Basel, Switzerland

Pfizer Inc. (NYSE:PFE), New York, N.Y.

Plexxikon Inc., Berkeley, Calif.

University of California, San Francisco, Calif. 